\title{
Cone dystrophies with negative photopic electroretinogram
}

\author{
Ulrich Kellner, Michael H Foerster
}

\begin{abstract}
A scotopic electroretinogram with an a-wave amplitude larger than the b-wave amplitude traditionally is termed 'negative'. Six male patients with negative photopic electroretinograms were examined; three of them suffered from progressive cone dystrophy, in which negative electroretinograms are unusual. Another patient without symptoms was the brother of a patient with cone dystrophy. These patients are compared with others who characteristically have negative electroretinograms - one patient with incomplete congenital stationary night blindness and another with $X$ linked congenital retinoschisis. Differential diagnosis between these unusual cases of cone dystrophies and $\mathrm{X}$ linked retinoschisis or congenital stationary night blindness was possible with funduscopy, adaptometry, and evaluation of progression, but not with the electroretinogram. Inner retinal defects may occur in cone dystrophies as indicated by the negative electroretinogram. The waveform variations between our patients may be due to different inner retinal defects. The findings in two brothers indicate that cone dystrophy and inner retinal defects may be inherited separately.

(Br F Ophthalmol 1993; 77: 404-409)
\end{abstract}

Cone dystrophies are a group of diseases involving the function of retinal cones in various ways. ${ }^{12}$ Several different primary defects within the retina seem to exist: degenerations can be separated according to the retinal area and cone types affected. Different involvement of central and peripheral cones has been described. ${ }^{34}$ Recently selective cone dystrophies affecting only one or two cone types have been separated from generalised cone dystrophies. ${ }^{5-7}$ In inherited retinal degenerations, however, the location of the primary retinal defect has always been attributed to the photoreceptor-retinal pigment epithelium complex. ${ }^{2}$

Occasionally electroretinographic findings were described, that indicated a dysfunction of inner retinal layers in cone dystrophies, ${ }^{8-10}$ yet, these findings were ignored. In those cases the bwave was severely reduced compared with a normal or moderately reduced a-wave, resulting in a 'negative' photopic electroretinogram. ${ }^{11}$ Similar electroretinograms were seen in incomplete congenital stationary night blindness, ${ }^{12-16}$ and $\mathrm{X}$ linked congenital retinoschisis. ${ }^{17}{ }^{18}$

We analysed retrospectively the records of three patients who suffered from cone dystrophies, had a negative photopic electroretinogram, and in whom $X$ linked retinoschisis and congenital stationary night blindness could be excluded. The patients are compared with patients with incomplete congenital stationary night blindness and $\mathrm{X}$ linked retinoschisis.

Electrophysiological methods

The electro-oculographic technique was as described by Rhode et al. ${ }^{19}$ The normal range of the light peak/baseline ratio was 187 (SD 36)\% ( \pm 2 $\mathrm{SD})$; therefore the lower limit of the normal range was $151 \%$.

The electroretinographic recording method has been described in detail. ${ }^{1820}$ The recording protocol includes all stimuli specified by the
Figure 1

Electroretinographic recordings from a normal person and cases $1-3$ (progressive cone dystrophies). In the upper rows the responses to increasing stimulus intensities when dark intensities when dark In the middle the responses at light adaptation (LA) and below the $30 \mathrm{~Hz}$ ficker response. The lines below the recordings indicate stimulus duration and numbers in front of the recordings stimulus intensities. Vertical calibration mark indicates $100 \mu \mathrm{V}$. Horizontal calibration mark indicates $20 \mathrm{~ms}$ for single-flash recordings and $50 \mathrm{~ms}$ for flicker stimulation.
DA

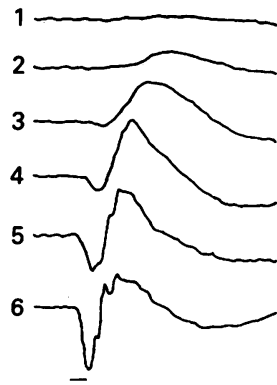

Case 1

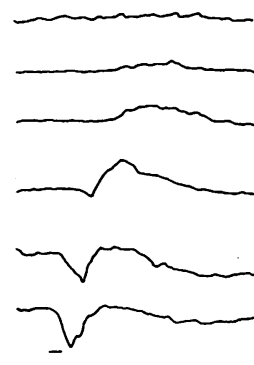

LA
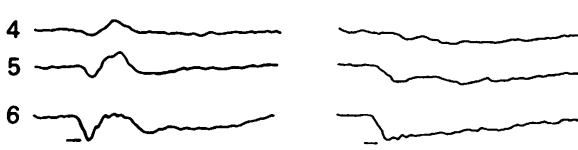

$30 \mathrm{~Hz}$
Case 2

Case 3
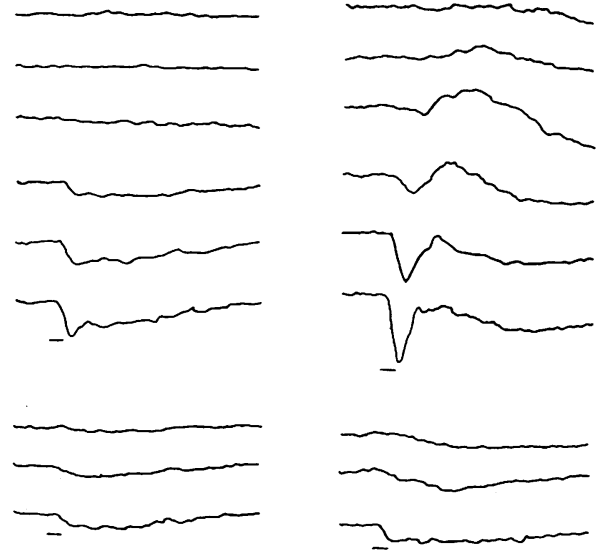
standard for clinical electroretinography. ${ }^{21}$ Stimulus duration was $10 \mathrm{~ms}$. Six different light intensities (1-6) increasing in steps of one logarithmic unit from the $b$-wave threshold of the normal eye were used for the dark adapted recordings. The maximum light intensity was $7 \cdot 8 \mathrm{~cd} \cdot \mathrm{s} / \mathrm{m}^{2}$. The light adapted recordings were performed under white light adaptation to a background of $4.5 \mathrm{~cd} \cdot \mathrm{m}^{-2}$ and with the light stimuli 4-6. The $30 \mathrm{~Hz}$ flicker stimulus had the light intensity 5 . White light from a xenon light source served as stimulus in all examinations. The light source was filtered for infrared with Schott filter KG2IR. A normal electroretinogram is shown in Figure 1. The normal ranges consist of the mean value $( \pm 2$ SD) from 40 volunteers.

\section{Clinical findings}

The clinical and electrophysiological findings of our patients are summarised in Table 1. The general and medical history was unremarkable in all patients. Acquired retinal degenerations owing to drug toxicity or infectious diseases like chorioretinitis or uveitis could be excluded.

\section{CASE 1 (PROGRESSIVE CONE DYSTROPHY)}

The 61-year-old patient suffered from progressive visual loss for more than 10 years. His visual acuity was 0.4 in both eyes. Pigment irregularities were seen in the macular area; the peripheral retina was normal. Visual field testing revealed paracentral scotomas in both eyes. He was unable to identify the Ishihara plates and the Panel D15 desaturé test. Testing with the Nagel anomaloscope revealed a deuteranomalous loss with a broad range of matches for the right (20$73 / 13)$ and left eye (30-67/13). The light rise of the electro-oculogram was reduced.

\section{CASE 2 (PROGRESSIVE CONE-ROD DYSTROPHY)}

The patient was first examined because of a corneal injury on the left eye at the age of 35 years. He had no visual problems at that time. Visual acuity was 1.0 on the right eye and 0.6 on the left owing to a corneal epithelial erosion. The funduscopic appearance was described as normal. Eight years later the patient was seen with a 5 year history of progressive visual loss. His visual acuity was reduced to 0.3 in both eyes. The intraocular pressure was normal as it was at the first examination. Fundus examination revealed paleness of the optic disc and a narrowing of the vessels. The visual fields showed a slight concentric narrowing in both eyes. Colour vision was severely disturbed. Ishihara plates could not be read. Panel D15 and FarnsworthMunsell 100 hue tests showed several errors without a typical axis. With the Nagel anomaloscope he found matches in accordance with achromatopsia. Dark adaptation, tested with the Goldmann-Weekers adaptometer, was reduced by 1.5 logarithmic units. The light rise of the electro-oculogram was reduced. The progressive visual loss excludes the diagnosis of congenital stationary night blindness in this patient.

\section{CASE 3 (PROGRESSIVE CONE DYSTROPHY)}

A short overview of the clinical findings and the results of colour electroretinography of this

Table 1 Clinical and electrophysiological findings in patients with negative photopic electroretinogram

\begin{tabular}{|c|c|c|c|c|c|c|c|c|c|c|c|c|c|c|c|}
\hline \multirow[b]{2}{*}{ No } & \multirow[b]{2}{*}{ Age } & \multirow[b]{2}{*}{ Sex } & \multirow[b]{2}{*}{ Prog } & \multirow[b]{2}{*}{ Eye } & \multirow[b]{2}{*}{$V A$} & \multirow[b]{2}{*}{ Refra } & \multirow[b]{2}{*}{ Fund } & \multirow[b]{2}{*}{ Colour } & \multirow[b]{2}{*}{$V F$} & \multirow[b]{2}{*}{$D A$} & \multirow[b]{2}{*}{$E O G$} & \multicolumn{2}{|l|}{$E R G$} & \multirow[b]{2}{*}{$30 \mathrm{~Hz}$} & \multirow[b]{2}{*}{$D x$} \\
\hline & & & & & & & & & & & & $d-b / a$ & $l-b / a$ & & \\
\hline 1 & 61 & $\mathbf{m}$ & ++ & $\begin{array}{l}\mathbf{R} \\
\mathbf{L}\end{array}$ & $\begin{array}{l}0.4 \\
0.4\end{array}$ & $\begin{array}{l}+3 \cdot 0 \\
+3 \cdot 25\end{array}$ & PI & deut & cent & & $\begin{array}{l}144 \\
144\end{array}$ & bord & red & 40 & $\mathrm{~cd}$ \\
\hline 2 & 43 & $\mathbf{m}$ & +++ & $\begin{array}{l}\mathbf{R} \\
\mathbf{L}\end{array}$ & $\begin{array}{l}0.3 \\
0.3\end{array}$ & $\begin{array}{l}-1.25 \\
-1.25\end{array}$ & PC & achr & conc & $3 \cdot 0$ & $\begin{array}{l}131 \\
128\end{array}$ & red & PIII & 0 & crd \\
\hline 3 & 40 & $\mathbf{m}$ & + & $\begin{array}{l}\mathbf{R} \\
\mathbf{L}\end{array}$ & $\begin{array}{l}0.4 \\
0.3\end{array}$ & $\begin{array}{l}+1.25 \\
+1.25\end{array}$ & PI & achr & cent & $\mathrm{n}$ & $\begin{array}{l}125 \\
128 \\
128\end{array}$ & red & PIII & 60 & $\mathrm{~cd}$ \\
\hline 4 & 44 & $\mathbf{m}$ & - & $\begin{array}{l}\bar{R} \\
\mathbf{L}\end{array}$ & $\begin{array}{l}1.0 \\
0.04\end{array}$ & $\begin{array}{l} \pm 0 \\
+7 \cdot 5\end{array}$ & $\mathbf{n}$ & $\mathbf{n}$ & $\mathbf{n}$ & $\mathbf{n}$ & $\begin{array}{l}135 \\
133\end{array}$ & red & red & 90 & $?$ \\
\hline 5 & 33 & $\mathbf{m}$ & - & $\begin{array}{l}\mathbf{R} \\
\mathbf{L}\end{array}$ & $\begin{array}{l}0.4 \\
0.4\end{array}$ & $\begin{array}{l}-2.5 \\
-3.25\end{array}$ & $\mathbf{n}$ & deut & $\mathbf{n}$ & $2 \cdot 9$ & $\begin{array}{l}150 \\
146\end{array}$ & red & red & 20 & csnb \\
\hline 6 & 29 & $\mathrm{~m}$ & - & $\begin{array}{l}\mathbf{R} \\
\mathbf{L}\end{array}$ & $\begin{array}{l}0.4 \\
0.2\end{array}$ & $\begin{array}{l}+2 \cdot 0 \\
+3.0\end{array}$ & $\mathbf{R}$ & dist & $\mathbf{n}$ & & $\begin{array}{l}183 \\
185\end{array}$ & red & red & 65 & $x \mid r$ \\
\hline Gl & 35 & $\mathrm{~m}$ & ++ & $\begin{array}{l}\mathbf{R} \\
\mathbf{L}\end{array}$ & $\begin{array}{l}0 \cdot 1 \\
0 \cdot 1\end{array}$ & $\begin{array}{l}-4 \cdot 0 \\
-3.75\end{array}$ & $\mathrm{BE}$ & achr & cent & & $\mathrm{n}$ & $\mathrm{n}$ & red & & $c d$ \\
\hline G2 & 28 & $\mathrm{~m}$ & ++ & $\begin{array}{l}\mathbf{R} \\
\mathbf{L}\end{array}$ & $\begin{array}{l}0.3 \\
0.25\end{array}$ & $\begin{array}{l}-1.5 \\
-1.5\end{array}$ & $\mathrm{n}$ & dist & para & & $\mathbf{n}$ & $\mathrm{n}$ & red & & $\mathrm{cd}$ \\
\hline G3 & 25 & f & + & $\begin{array}{l}\mathbf{R} \\
\mathbf{L}\end{array}$ & $\begin{array}{l}0.5 \\
0.25\end{array}$ & $\begin{array}{l}-0.5 \\
-0.5\end{array}$ & $\mathrm{BE}$ & achr & para & & red & $\mathbf{n}$ & red & & $\mathrm{cd}$ \\
\hline G4 & 28 & $\mathbf{m}$ & ++ & $\begin{array}{l}\mathbf{R} \\
\mathbf{L}\end{array}$ & $\begin{array}{l}0.25 \\
0.1\end{array}$ & $\begin{array}{l}-2.75 \\
-3.5\end{array}$ & $\mathrm{BE}$ & achr & para & & red & $\mathbf{n}$ & red & & $c d$ \\
\hline G5 & 22 & f & & $\begin{array}{l}\mathbf{R} \\
\mathbf{L}\end{array}$ & $\begin{array}{l}0.7 \\
0.7\end{array}$ & $\begin{array}{l} \pm 0 \\
\pm 0\end{array}$ & $\mathrm{BE}$ & dist & para & & $\mathrm{n}$ & $\mathbf{n}$ & red & & $\mathrm{cd}$ \\
\hline Y & 44 & f & - & $\begin{array}{l}\bar{R} \\
\mathbf{L}\end{array}$ & $\begin{array}{l}0.8 \\
0.8\end{array}$ & & PC & dist & peri & $\mathrm{n}$ & & $\mathbf{n}$ & red & red & $?$ \\
\hline W1 & 35 & $\mathbf{m}$ & & $\begin{array}{l}\mathbf{R} \\
\mathbf{L}\end{array}$ & $\begin{array}{l}0.7 \\
0.7\end{array}$ & & $\mathrm{BE}$ & dist & & & $\mathbf{n}$ & $\mathbf{n}$ & red & red & $\mathrm{cd}$ \\
\hline W2 & 18 & $\mathrm{~m}$ & & $\begin{array}{l}\mathbf{R} \\
\mathrm{L}\end{array}$ & $\begin{array}{l}0.2 \\
0.06\end{array}$ & & $\mathrm{BE}$ & dist & & & $\mathbf{n}$ & $\mathbf{n}$ & red & red & $\mathrm{cd}$ \\
\hline W3 & 38 & m & & $\begin{array}{l}\mathbf{R} \\
\mathbf{L}\end{array}$ & $\begin{array}{l}0.02 \\
0.02\end{array}$ & & PC & dist & & & red & $\mathbf{n}$ & red & red & $\mathrm{cd}$ \\
\hline
\end{tabular}

Visual acuity at the last follow-up examination, refraction, and the light rise of the electro-oculogram is given for both eyes separately. All other values were given once for a patient if there was no difference between both eyes. Empty fields indicate missing dates. Normal range: electro-oculography: 187 (SD 36)\% (lower limit, $151 \%$ ); $30 \mathrm{~Hz}$ flicker response: 136 (SD 52) $\mu \mathrm{V}$ (lower limit $84 \mu \mathrm{V}$ ). Gl-5 = patients of Grey et al ${ }^{8}$; Y = patient of Young et al ; Wl-3=patients of Wakabayashi ${ }^{10}$. Prog=progression; VA=visual acuity; Refra=refraction; Fund = funduscopic findings; VF =visual fields; DA = dark adaptation; EOG = electro-oculogram; ERG = electroretinogram; $30 \mathrm{~Hz}=30 \mathrm{~Hz}$ flicker amplitude; $\mathrm{Dx}=$ diagnosis; $d=$ dark; $1=$ light adapted; $m=$ male; $\mathrm{f}=\mathrm{female} ; \mathrm{PI}=$ pigment irregularities; $\mathrm{PC}=$ pigment clumping; $\mathrm{n}=$ normal; $\mathrm{R}=$ retinoschisis $; \mathrm{BE}=$ bull's eye; deut $=$ deuteranopia; achr $=$ achromatopsia; dist $=$
disturbed without specific axis; conc $=$ concentric narrowing; cent $=$ central scotoma; para = paracentral scotoma; peri $=$ peripheral scotoma; bord = borderline; red = reduced; PIII = PIII component cd=cone dystrophy; $c$ rd = cone rod dystrophy; csnb=congenital

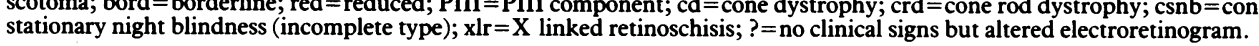


patient have been described previously as cone dystrophy with missing b-waves at light adaptation. ${ }^{7} \mathrm{He}$ has been observed for 22 years, beginning at the age of 18 years. He had complained of reduced visual acuity since childhood. The visual acuity was 0.5 in the right eye and 0.4 in the left at the first examination and 0.4 in the right and 0.3 in the left at the last follow up. Mild pigment irregularities in the macular area remained unchanged. Central scotomas were found in both eyes. Colour vision testing revealed a protanomaly at the first examination. At the age of 40 achromatopsia was found on the Nagel anomaloscope and the FarnsworthMunsell 100 hue test. The dark adaptation had a normal final threshold. The electro-oculogram showed a reduced light rise. Although the visual acuity was relatively stable, the progressive colour vision deficiency indicates a slow progressive cone dystrophy in this patient.

\section{CASE 4 (FAMILY MEMBER)}

The brother of case 3 was examined at the age of 44 years. His visual acuity was 1.0 in the right eye and 0.04 in the left owing to anisometropia of $+7 \cdot 5$ dioptres. The funduscopic appearance was normal as were the visual fields, colour vision, and dark adaptation. The light rise of the electrooculogram was reduced.

CASE 5 (INCOMPLETE CONGENITAL STATIONARY NIGHT BLINDNESS)

The 33-year-old patient had a reduced visual acuity and difficulties with seeing at night without progression since childhood. He had a visual acuity of 0.4 in both eyes. The funduscopic appearance and the visual fields were normal. Deuteranopia was revealed by the Nagel anomaloscope. Dark adaptation measured with the Goldmann-Weekers adaptometer showed a reduced final threshold at 1.6 logarithmic units. The light rise of the electro-oculogram was reduced.

CASE 6 (X LINKED RETINOSCHISIS)

This 29-year-old man suffering from $\mathrm{X}$ linked congenital retinoschisis is a representative example from a recently described series. ${ }^{18} \mathrm{His}$ two brothers were also affected. His visual acuity was 0.4 on the right and 0.2 on the left eye. Both eyes showed a macular retinoschisis with normal periphery. The visual fields were normal. Colour vision was disturbed with misreading of four Ishihara plates and an extensive range of matches from $34 / 13$ to $48 / 13$ at the Nagel anomaloscope. The light rise of the electro-oculogram was normal in both eyes.

\section{Electroretinographic findings}

In Figures 1 and 2 the electroretinographic recordings are shown and in Figures 3-6 the amplitude-intensity functions of all patients are given. An overview of the electrophysiological findings including the $30 \mathrm{~Hz}$ flicker amplitudes is listed in Table 1 for comparison with the patients described in the literature.

\section{CASE 1}

In case 1 the a-wave amplitudes were borderline at lower stimulus intensities and subnormal at the higher stimulus intensities when dark adapted. The b-wave amplitudes were reduced at all stimulus intensities and therefore the $b / a$ ratios were borderline. When light adapted, the a-wave amplitudes were normal, but the b-wave amplitudes and b/a ratios were severely reduced. The $30 \mathrm{~Hz}$ flicker amplitude was reduced. The awave latencies were normal, the b-wave implicit times were delayed at dark adaptation.

\section{CASE 2}

In case 2 the electroretinogram showed borderline a-wave amplitudes at lower stimulus intensities and subnormal amplitudes at higher intensities at dark and light adaptation. When dark adapted, small b-waves were found at higher stimulus intensities and accordingly the b/a ratios were severely reduced. The implicit times of these b-waves were $30-34 \mathrm{~ms}$ in both eyes without difference between the stimulus intensities 5 and 6 . These implicit times were about $8 \mathrm{~ms}$ shorter than the implicit time of the
Figure 2

Electroretinographic recordings from a normal person and case 4 (family member), case 5 (congenital stationary night blindness, and case 6 (X linked retinoschisis). For detailed explanation see Figure 1.
DA

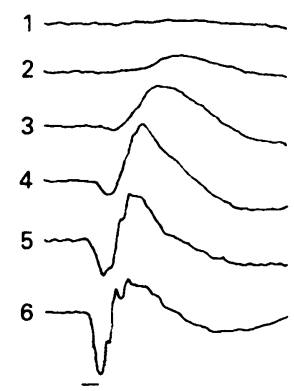

LA

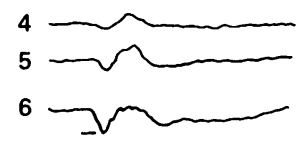

$30 \mathrm{~Hz}$
Case 4

Case 5
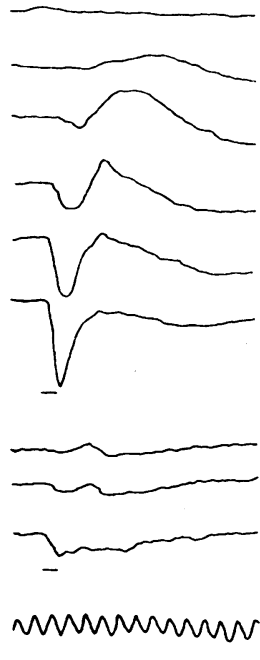

Case 6
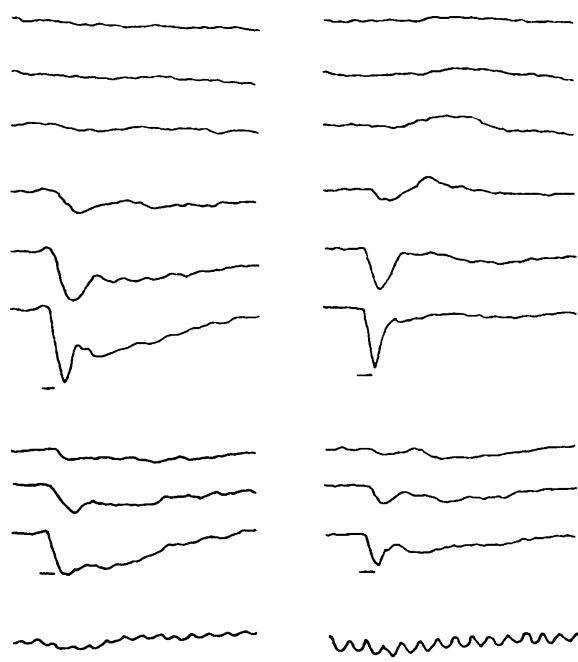

numonom $L$ 
Figure 3 Dark adapted awave amplitudes in patients with negative photopic

electroretinograms. Three patients with progressive cone dystrophy and a family member: case 1 ( $\square)$, case 2

$(\square)$, case $3(\mathrm{O})$, and the brother of case 3 (case 4, One patient with incomplete congenital stationary night blindness (case 5, $\triangle$ ), and one patient with $X$ linked congenital retinoschisis (case $6, \Delta)$. The normal range indicated by two lines is the mean value $( \pm 2 S D)$. The stimulus intensity is indicated on the horizontal axis.

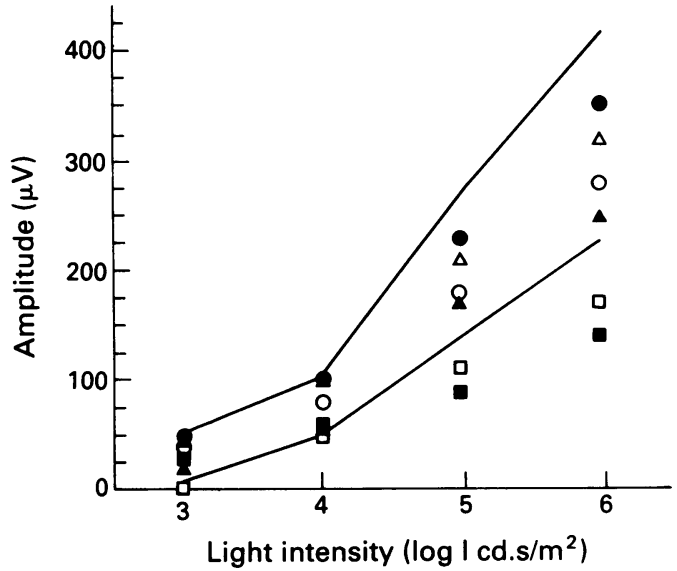

b-wave in normals, which is 42 (SD 1.8) $\mathrm{ms}$ at stimulus intensity 5 , and 39 (SD 1.4) $\mathrm{ms}$ at stimulus intensity 6 . At light adaptation a-waves and no measurable b-waves were present. The responses, therefore, looked like an isolated PIII-component, which corresponds to the photoreceptor response. ${ }^{22}$ There was no response to $30 \mathrm{~Hz}$ flicker stimulation.

\section{CASE 3}

In case 3 the a-wave amplitudes were normal when dark adapted and borderline when light adapted. The b-wave amplitudes were borderline at lower stimulus intensities and reduced at stimulus intensities 4-6 when dark adapted. The $\mathrm{b} / \mathrm{a}$ ratios were reduced at all stimulus intensities when dark adapted. At light adaptation no bwaves were measurable. The latencies and implicit times of a- and b-waves, when present, were normal. The $30 \mathrm{~Hz}$ flicker response was reduced. The electroretinogram was unchanged within the last 3 years of follow up. Tested with colour stimuli in the electroretinogram and psychophysically, this patient had a severe red cone dysfunction and only a moderate green cone dysfunction.

CASE 4

In case 4 the a-wave amplitudes were normal at all recording conditions. The b-wave amplitudes were normal at lower stimulus intensities when

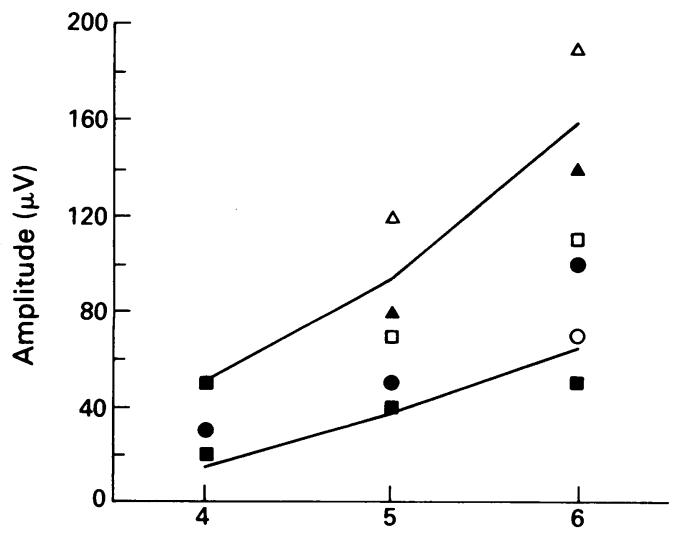

Light intensity $\left(\log \mid \mathrm{cd} . \mathrm{s} / \mathrm{m}^{2}\right)$

Figure 4 Light adapted a-wave amplitudes in patients with negative photopic electroretinograms. For further explanation see Figure 3 .

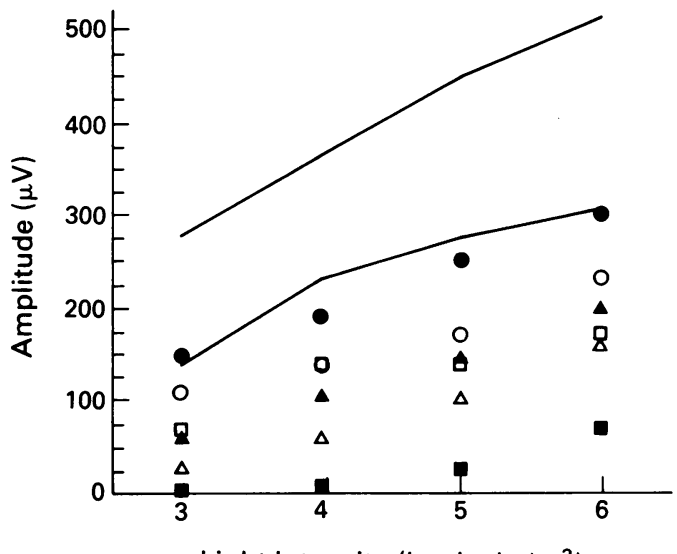

Light intensity $\left(\log 1 \mathrm{~cd} . \mathrm{s} / \mathrm{m}^{2}\right)$

Figure 5 Dark adapted b-wave amplitudes in patients with negative photopic electroretinograms. For further explanation see Figure 3.

dark adapted. They were reduced just below the lower limit of the normal range at high stimulus intensities when dark adapted and under light adapted conditions. The b/a ratios were reduced when dark adapted. When light adapted, they were borderline at lower stimulus intensities and reduced at maximum stimulus intensity. The latencies and implicit times of a- and b-waves were normal. The $30 \mathrm{~Hz}$ flicker response was within the lower normal range.

\section{CASE 5}

Case 5 had normal a-wave amplitudes at dark adaptation and large amplitudes at light adaptation. The b-waves were reduced in all stimulus conditions and so were the b/a ratios. The b-wave implicit time was short $(27 \mathrm{~ms})$ at the highest stimulus intensity when dark adapted and was normal in all other recordings. The $30 \mathrm{~Hz}$ flicker response was severely reduced.

\section{CASE 6}

Case 6 showed normal a-waves in all recordings. The b-waves were reduced when dark adapted and normal when light adapted. The b/a ratios were reduced in all recordings. The latencies and implicit times of a- and b-waves were normal. The $30 \mathrm{~Hz}$ flicker response was reduced. It should be noted that in this and all other

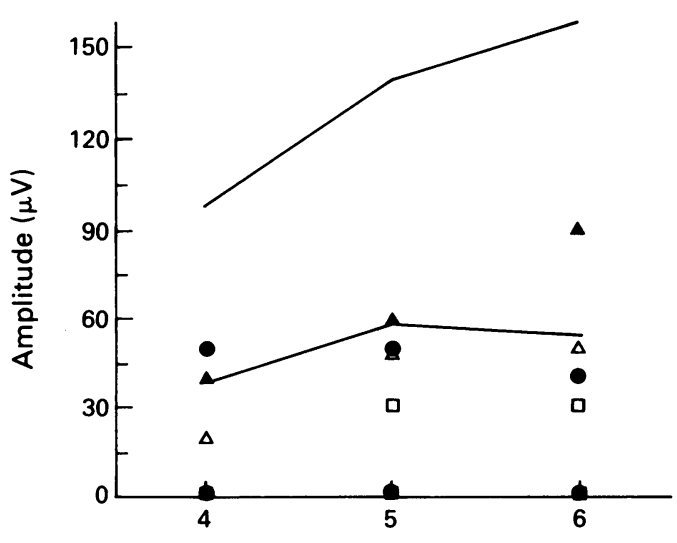

Light intensity $\left(\log \mid \mathrm{cd} . \mathrm{s} / \mathrm{m}^{2}\right)$

Figure 6 Light adapted b-wave amplitudes in patients with negative photopic electroretinograms. For further explanation see Figure 3. 
previously examined patients with $\mathrm{X}$ linked retinoschisis ${ }^{18}$ a small $b$-wave was always present when light adapted.

\section{Discussion}

A 'negative' electroretinogram has been defined as a waveform in which the a-wave amplitude is larger than the b-wave amplitude, resulting in a b/a ratio below $1 \cdot 0 .{ }^{11}$ At dark adapted conditions, a negative electroretinogram is a typical finding in different forms of congenital stationary night blindness, ${ }^{12-16} \mathrm{X}$ linked congenital retinoschisis, ${ }^{17}{ }^{18}$ central retinal vein occlusion, ${ }^{11}$ and quinine intoxication..$^{23} \mathrm{~A}$ negative electroretinogram may be seen in early cases of retinitis pigmentosa $^{24}$ and rarely with other conditions: an overview has been presented recently by Weleber. ${ }^{15}$ With light adaptation, a negative electroretinogram can be found in the same disorders to a much lesser extent than with dark adapted conditions, with the exception of incomplete congenital stationary night blindness. ${ }^{14}$

Only a few cases with predominantly cone dysfunction and negative photopic electroretinogram have been mentioned in the literature. ${ }^{8-10}$ An overview of the clinical and electrophysiological findings in these patients is listed in Table 1 for easier comparison with our cases. The eight cases of Grey and Wakabayashi suffered from cone dystrophies. ${ }^{810}$ They had reduced visual acuity, colour vision defects, bull's eye lesions or pigment irregularities in the macula, and central or paracentral scotomas. The light rise of the electro-oculogram was either normal or reduced. The electroretinogram at dark adaptation was described as normal. Stimulus conditions are different and were not described in detail. Obviously much weaker stimuli were used. In our patients the reduction of the scotopic b-wave was better seen with higher stimulus intensities. These eight cases are comparable with our cases 1-3. In contrast to our series two of them were female. Young described another female patient with negative photopic electroretinogram without symptoms ${ }^{9}$; therefore she may be comparable with our case 4 . In contrast to our patient she had widespread pigment clumping on the fundus and visual field defects, and a progression could be possible. Her dark adapted electroretinogram was reduced to about $50 \%$ with a normal b/a ratio.

In our series all five patients with clinical signs (cases 1-3, 5, and 6) had a dysfunction of the cones or the cone pathways. The visual acuity was reduced, colour vision defective, and in the electroretinogram the $30 \mathrm{~Hz}$ flicker response was reduced. The negative electroretinogram was more pronounced in all of our six cases with light adapted compared with dark adapted conditions. There was only one apparent difference in the electroretinographic waveforms between patients with cone dystrophies, incomplete congenital stationary night blindness, and $\mathrm{X}$ linked retinoschisis. In two patients with cone dystrophies (cases 2 and 3) only a PIII component with no detectable b-wave was found. A PIII component with no detectable b-wave can occur in incomplete congenital stationary night blind- ness. ${ }^{13}$ In $\mathrm{X}$ linked retinoschisis a small $\mathrm{b}$-wave is always present. ${ }^{18}$

The photopic electroretinogram is the result of cone responses, responses from depolarising and hyperpolarising bipolar cells from Müller cells, and possibly other retinal cell types. The a-wave corresponds to the beginning of the PIII component. The severely reduced $b$-waves indicate a disturbance in the proximal retinal layers either in the cone pathway or in the Müller cells. Similar electroretinographic findings as in our patients have been seen in rhesus monkeys in which APB (2-amino-4-phosphonobutyric acid) was injected intravitreally. ${ }^{25}$ APB selectively blocks depolarising bipolar cells without affecting the hyperpolarising bipolar cells. In X linked retinoschisis histological findings indicate a defect of the Müller cells. ${ }^{26}$

The inner retinal defect is not necessarily combined with the defect that causes receptor dysfunction. In case 3 the electroretinographic findings indicate receptor and inner retinal defects. The brother (case 4) had normal cone function, but showed a negative photopic electroretinogram. The cone dystrophy and the inner retinal defect, therefore, can be inherited separately.

Not all properties of the cone pathways are similar in our cases with cone dystrophies, and this may indicate different inner retinal defects. Interestingly, one of two patients with no measurable b-wave at light adaptation had a moderately reduced $30 \mathrm{~Hz}$ flicker amplitude of $60 \mu \mathrm{V}$ (case 3); the other one had no flicker response at all (case 2). The flicker response is generally regarded as the cone b-wave. ${ }^{27}$ However, how can a flicker response persist when the b-wave is missing? Maybe the bipolar cells respond in a different way to flicker stimulation than to single flashes.

The findings in our patients indicate that additional inner retinal transmission defects in the cone pathway can occur in cone dystrophies. These patients present with reduced visual acuity, colour vision defects, a reduced $30 \mathrm{~Hz}$ flicker response, and a negative photopic electroretinogram. The most important differential diagnoses are incomplete congenital stationary night blindness and $\mathrm{X}$ linked congenital retinoschisis. The electroretinographic findings, however, do not allow a separation of these diseases. Diagnosis is only possible with evaluation of progression, funduscopic findings, and testing of dark adaptation.

1 Goodman G, Ripps $\mathrm{H}$ Siegel I Cone dysfunction syndromes. Arch Ophthalmol 1963; 70: 214-31.

2 Heckenlively JR Cone dystrophies and dysfunction. In: Heckenlively JR, Arden GB, eds. Principles and practice of clinical electrophysiology of vision. St Louis: Mosby, 1991: 537-43.

3 Pinckers A, Deutman AF. Peripheral cone disease. Ophthalmologica 1977; 174: 145-50.

4 Yagasaki K, Jacobson SG. Cone rod dystrophy. Phenotypic diversity by retinal function testing. Arch Ophthalmol 1989; 107: 701-8.

5 Reichel E, Bruce AM, Sandberg MA, Berson EL. An electroretinographic and molecular genetic study of $\mathrm{x}$-linked cone degeneration. Am 7 Ophthalmol 1989; 108: 540-7.

6 Kellner U, Foerster MH. Netzautd Blauzapfenhypersensitivität. Fortsch Ophthalmol 1991; 88:

7 Kellner U, Foerster MH. Color electroretinography - a method for separation of dysfunctions of cones. Doc method for separation of

8 Grey RHB, Blach RK, Barnard WM. Bull's eye maculopathy with early cone degeneration. $\mathrm{Br} \mathcal{F}$ Ophthalmol 1977; 61: 702-18. 
9 Young R, Price J, Gorham N, Cowart M. Selective abnormality of the cone b-wave in a patient with retinal degeneration. Doc Ophthalmol 1985; 60: 211-8.

10 Wakabayashi K. Electrodiagnosis of primary macular dystrophies. F Fuzen Med Soc 1986; 96: 399-439.

11 Karpe G. The basis of clinical electroretinography. Acta Ophthalmol 1945; 24 (suppl): 1-118.

12 Schubert G, Bornschein H. Beitrag zur Analyse des menschlichen Elektroretinogramms. Ophthalmologica 1952; 123: 396-413.

13 Miyake Y, Yagasaki K, Horiguchi M, Kawase Y, Kanda T Congenital stationary night blindness with negative electroretinogram. A new classification. Arch Ophthalmol 1986; 104: 1013-20.

14 Miyake Y. Incomplete type congenital stationary night blindness. In: Heckenlively JR, Arden GB, eds. Principles and practice of clinical electrophysiology of vision. St Louis: Mosby, 1991: 721-5.

15 Weleber RG, Pillers DAM, Powell BR, Hanna CE, Magenis RE, Buist NRM. Aland Island eye disease (Forsius-Eriksson syndrome) associated with contiguous deletion syndrome Syndrome) associated with contiguous deletion syndrome at blindness. Arch Ophthalmol 1989; 107: 1170-9.

16 Young RSL. Low-frequency component of the photopic ERG in patients with $x$-linked congenital stationary night blindin patients with $x$-linked congenital

17 Hirose T, Wolf E, Hara A. Electrophysiological and psychophysical studies in congenital retinoschisis of $\mathrm{x}$-linked recessive inheritance. Doc Ophthalmol Proc Ser 1977; 13: 173-84.
18 Kellner U, Brümmer S, Foerster MH, Wessing A. X-linked congenital retinoschisis. Graefes Arch Clin Exp Ophthalmo 1990 ; 228: 432-7.

19 Rhode N, Täumer R, Pernice D. Vorschlag eines verbesserten klinischen EOG-Testes. Ber Dtsch Ophthalmol Ges 1977; 74: 747-50.

20 Foerster MH, Kellner U, Wessing A. Cone dystrophy and supernormal dark-adapted b-waves in the electroretinogram. Graefes Arch Clin Exp Ophthalmol 1990; 228: gram.

21 Marmor MF, Arden GB, Nilsson SEG, Zrenner E. Standard for clinical electroretinography. Arch Ophthalmol 1989; 107: 816-9.

22 Granit $\mathbf{R}$. Sensory mechanisms of the retina. London: Oxford University Press, 1947.

23 Bacon P, Spalton DJ, Smith SE. Blindness from quinine toxicity. Brf Ophthalmol 1988; 72: 219-24.

$24 \mathrm{Krill}$ AE. Hereditary retinal and choroidal diseases. Vol II. Hagerstown: Harper \& Row, 1977: 403-4.

25 Smith EL, Harwerth RS, Crawford MLJ, Duncan GC Contribution of the retinal ON channels to scotopic and photopic spectral sensitivity. Vis Neurosci 1989; 3: 22539 .

26 Condon GP, Brownstein S, Wang NS, Kearns AF, Ewing CC. Congenital hereditary (juvenile $\mathrm{x}$-linked) retinoschisis. Histopathologic and ultrastructural findings in three eyes. Arch Ophthalmol 1986; 104: 576-83.

27 Birch DG. Flicker electroretinography. In: Heckenlively JR, Arden GB, eds. Principles and practice of clinical electrophysiology of vision. St Louis: Mosby, 1991: 348-51.

\section{History of ophthalmology}

\section{On private practice}

Those who sometimes feel overwhelmed by the financial and logistic complications of private practice, may safely direct their ire at Hammurabi, who seems to have started the whole business in $2500 \mathrm{BC}$ by publishing the following table of fees:

'Setting of man's broken bone' - 5 Shekels

'Setting freeman's bone' -3 Shekels

'Setting slave's bone' -2 Shekels

'Treating ox or ass' - 1/6 Shekel

This should actually cheer up one's accountant, as today's fees aren't tailored to patients' income (whether the NHS soon will be is a moot point). And we don't treat oxen - in fact are legally prevented from doing so. Whether we ever treat asses is a matter of opinion.

Private practice has been a lucrative business for centuries. Pope Clement V had to forbid medical practice by ecclesiastical persons, as it was so financially rewarding that all the monks were leaving the monasteries to practise full time. There weren't many bishops left, either.

A little later, many Tudor doctors were able to purchase country estates with their earnings. But this situation becomes less desirable when the reason for such high fees is known - they had to reside in the patient's house 'until all suppuration had healed.' One such experience with a 'heartsink' patient could undoubtedly break a practitioner.

During many periods of history, payment was only made for successful operations. Oph- thalmologists in Babylon received no shekels at all (and occasionally had their hands hacked off) if the patients' sight did not return. This must have imbued the postoperative ward rounds with a certain tension. One wonders whether they had insurance for 'loss of income owing to disablement.'

Collection of the fee has long been fraught with difficulty. A Tudor surgeon advised that 'It is surer to be paid while the patient is not entirely well, as the outstretched hand may be drawn back after cure is complete.' This advice is hard to follow nowadays. For one thing, the ophthalmology private patient would be unable to write the cheque until the dressings came off.

The Tudors did have a system of legal redress, though. In 1537 Dr Andrew Boorde petitioned for the sum of $£ 53$, 'in money, cloth and two horses' which was owed to him. As the average annual wage was $£ 2$, Boorde could have hung up his instrument case and retired had he got it. Fortunately for medicine - as his later writings were excellent - he did not.

FIONA ROMAN

Gordon BL. Medieval and renaissance medicine. London: Peter Owen, 1959: 759-61.

Graham H. Surgeons all. London: Rich and Cowan, 1939: 33-8. Riesman D. Medicine in the middle ages. New York: Paul B Hoeber Inc, 1935: 17-27.

Sigerist HE. A history of medicine. New York: Oxford University Press, 1951: 246-52. 